\title{
Vital Signs: State-Level Variation in Nonfatal and Fatal Cardiovascular Events Targeted for Prevention by Million Hearts 2022
}

\author{
Matthew D. Ritchey, DPT ${ }^{1}$; Hilary K. Wall, $\mathrm{MPH}^{1}$; Pamela L. Owens, $\mathrm{PhD}^{2}$; Janet S. Wright, $\mathrm{MD}^{1}$
}

\begin{abstract}
Introduction: Despite its preventability, cardiovascular disease remains a leading cause of morbidity, mortality, and health care costs in the United States. This study describes the burden, in 2016, of nonfatal and fatal cardiovascular events targeted for prevention by Million Hearts 2022, a national initiative working to prevent one million cardiovascular events during 2017-2021.

Methods: Emergency department (ED) visits and hospitalizations were identified using Healthcare Cost and Utilization Project databases, and deaths were identified using National Vital Statistics System data. Age-standardized Million Hearts-preventable event rates and hospitalization costs among adults aged $\geq 18$ years in 2016 are described nationally and across states, as data permit. Expected 2017-2021 event totals and hospitalization costs were estimated assuming 2016 values remain unchanged.

Results: Nationally, in 2016, 2.2 million hospitalizations (850.9 per 100,000 population) resulting in $\$ 32.7$ billion in costs, and 415,480 deaths (157.4 per 100,000) occurred. Hospitalization and mortality rates were highest among men (989.6 and 172.3 per 100,000, respectively) and non-Hispanic blacks (211.6 per 100,000, mortality only) and increased with age. However, 805,000 hospitalizations and 75,245 deaths occurred among adults aged 18-64 years. State-level variation occurred in rates of ED visits (from 56.4 [Connecticut] to 274.8 per 100,000 [Kentucky]), hospitalizations (484.0 [Wyoming] to 1670.3 per 100,000 [DC]), and mortality (111.2 [Vermont] to 267.3 per 100,000 [Mississippi]). Approximately 16.3 million events and $\$ 173.7$ billion in hospitalization costs could occur during 2017-2021 without preventive intervention.

Conclusions and Implications for Public Health Practice: Million Hearts-preventable events place a considerable health and economic burden on the United States. With coordinated efforts, many of these events could be prevented in every state to achieve the initiative's goal.
\end{abstract}

\section{Introduction}

Heart disease and stroke are largely preventable (1-3). However, despite decades-long improvement in outcomes, they remain leading causes of morbidity, mortality, and health care costs in the United States (2). Moreover, considerable disparities persist and recent evidence suggests that heart disease and stroke event rates are increasing among certain demographic groups, including adults aged 35-64 years $(2,4)$. In response, CDC and the Centers for Medicare \& Medicaid Services launched Million Hearts 2022, a national initiative working to prevent one million heart attacks, strokes, and other acute cardiovascular events during 2017-2021 (1,5).

Million Hearts 2022, in collaboration with multiple federal, state, and nongovernmental partners, supports the implementation of a selected set of evidence-based public health and clinical strategies aimed at keeping adults healthy and optimizing care to prevent cardiovascular events. This includes using strategies that improve the "ABCS" (aspirin when appropriate, blood pressure control, cholesterol management, and smoking cessation) of cardiovascular care; reducing sodium consumption, tobacco use, and physical inactivity; improving care among persons who have had cardiovascular events*; and addressing known disparities in cardiovascular outcomes ${ }^{\dagger}$ (6). Despite their efficacy, implementation of these strategies throughout the country has been inconsistent, which might contribute to the disparities and geographic variation observed in cardiovascular disease (CVD) outcomes $(2,4)$.

\footnotetext{
* Includes use of cardiac rehabilitation among persons who have had a qualifying cardiac event or procedure and improving awareness of the potential negative health sequelae of and avoiding exposure to poor air quality among persons who have had a previous cardiovascular event.

$\dagger$ Includes improving hypertension control among blacks/African Americans and improving prevention and management of CVD risk factors among adults aged 35-64 years and persons with mental and/or substance use disorders who use tobacco.
} 
This study describes the distribution, by demographic characteristics and state, of nonfatal (emergency department [ED] visits and hospitalizations) and fatal cardiovascular events that occurred during 2016 and are being targeted for prevention by Million Hearts 2022. Furthermore, it provides a baseline for states by estimating the number of events and hospitalization costs expected to occur if 2016 rates remain unchanged during 2017-2021. These findings can be used by Million Hearts 2022 partners to understand the recent and potential future event burden if no further intervention occurs, and to focus their use of prevention strategies and assess the potential effect on cardiovascular event totals.

\section{Methods}

This study leverages a previously published methodology to identify mutually exclusive nonfatal and fatal cardiovascular events (Million Hearts-preventable events) among adults aged $\geq 18$ years attributed to acute myocardial infarctions, strokes, precursor cardiovascular conditions, and other cardiovascular conditions, by applying specified International Classification of Diseases, Tenth Revision (ICD-10) codes within administrative data (Supplementary Table 1, https://stacks.cdc.gov/ view/cdc/58170) (7). ${ }^{\S}$ Where data availability permit, event rates are described at the state and national levels for 2016 (most current available data). At the state level, the Agency for Healthcare Research and Quality's (AHRQ) Healthcare Cost and Utilization Project (HCUP) State Emergency Department Database (SEDD) was used to describe 2016 treat-and-release ED event rates for 34 states and the District of Columbia (DC)**

\footnotetext{
$\S$ Million Hearts-preventable ED visits and hospitalizations were defined as events where patients had one of the specified ICD-10-CM codes listed as their firstlisted/principal diagnosis (national implementation of ICD-10-CM codes occurred in October 2015); Million Hearts-related deaths were events with a specified ICD-10 code listed as the underlying cause of death (national implementation of ICD-10 mortality codes occurred in 1999). Precursor cardiovascular conditions include stable angina pectoris, transient ischemic attack, and other acute and subacute ischemic heart diseases. Other cardiovascular conditions include heart failure, abdominal aortic aneurysm, atheroembolism (hospitalizations only), atherosclerosis and peripheral artery disease (deaths only), hypertension without heart failure, and cardiac arrest that had another Million Hearts-preventable event type coded as a secondary diagnosis or contributing cause of death.

I AHRQ is a Million Hearts 2022 partner and supported the release of this report. Information about AHRQ's support of Million Hearts 2022 through their EvidenceNow initiative can be found at https://www.ahrq.gov/sites/ default/files/wysiwyg/evidencenow/about/evidence-now-fact-sheet.pdf.

** The SEDD (https://www.hcup-us.ahrq.gov/seddoverview.jsp) is an encounterbased, all-payer (including the uninsured) administrative database capturing claims for $78 \%$ of all $\mathrm{ED}$ visits that do not result in hospitalization at U.S. community, non-rehabilitation, acute care hospitals. In 2016, it included data from all states except Alabama, Alaska, Colorado, Delaware, Idaho, Louisiana, Michigan, Mississippi, New Hampshire, New Mexico, Oklahoma, Oregon, Pennsylvania, Virginia, Washington, and West Virginia; data for Mississippi and Oregon are regularly collected, but 2016 data were not available at the time of this report. Treat-and-release ED event rates represents ED visits that did not result in a hospitalization, and exclude visits where the patient died in the ED, was transferred to another hospital, or was admitted to the same hospital.
}

and the HCUP State Inpatient Database (SID) was used to describe 2016 acute, nonfatal hospitalization event rates for 46 states and DC. ${ }^{\dagger \dagger}$ Data to generate weighted national estimates for 2016 ED events were unavailable at the time of publication; these data ${ }^{\$ \$}$ will be used for national Million Hearts surveillance as they become available. Weighted national estimates and standard errors were determined for 2016 hospitalization events by using HCUP's National Inpatient Sample (NIS), 99 a database developed from data collected via the State Inpatient Database. The National Center for Health Statistics' National Vital Statistics System ${ }^{* * *}$ Mortality Data were used to describe 2016 mortality rates for the nation and all 50 states and DC.

Event rates were stratified by gender and age group (18-44, 45-64, 65-74, and $\geq 75$ years), race and Hispanic origin (mortality only ${ }^{\dagger \dagger}$ ), event type (acute myocardial infarction, stroke, precursor condition, and other condition), and state. $\$ \$ \$$ Overall mutually exclusive event rates equal the sum of the treat-and-release ED visits, acute, nonfatal hospitalizations, and deaths and are available for 35 jurisdictions with complete data. Rates were standardized by age to the 2010 U.S. Census. Costs associated with hospitalizations were determined by applying HCUP cost-to-charge ratios 99 to the hospital billing charges provided in the SID (state estimates) and NIS (national estimates) and are presented in 2016 US\$; these costs exclude professional (physician) fees. The mean cost per hospitalization was calculated and standardized by age and

†† The SID (https://www.hcup-us.ahrq.gov/sidoverview.jsp) is an encounterbased, all-payer (including the uninsured) administrative database capturing claims for $97 \%$ of all hospitalizations at U.S. community, nonrehabilitation, acute care hospitals. In 2016, it included data from all states except Alabama, Delaware, Idaho, and New Hampshire. To identify acute, nonfatal hospitalizations, hospitalizations that were reported as elective or where the patient died in the hospital or was transferred to another hospital were excluded.

$\$ \$$ For national Million Hearts surveillance weighted national ED visit rates are determined using HCUP's Nationwide Emergency Department Sample (NEDS) (https://www.hcup-us.ahrq.gov/nedsoverview.jsp), which contains data from 30.5 million ED visits from about 1,000 hospitals sampled to approximate a $20 \%$ stratified sample of U.S. hospital-based emergency departments. Weighted, there are approximately 143 million ED visits annually.

Is The NIS (https://www.hcup-us.ahrq.gov/nisoverview.jsp) approximates a $20 \%$ stratified sample of discharges from over 4,500 U.S. community hospitals. Weighted, there are approximately 36 million discharges annually.

*** https://www.cdc.gov/nchs/nvss/index.htm.

t† Race/ethnicity is consistently reported in the SEDD and SID for only 32 states and was therefore not included in the presentation of ED and hospitalization event rates.

$\$ \$ \$ S D$ and hospitalization events were assigned to the state the patient was treated in. Death events were assigned to the residence the individual lived in.

999 Charge information was available for ED and hospitalization events; however, charge amounts represent only what was billed for services and do not reflect how much the services actually cost the hospital to provide or the amount received in payment. Use of HCUP Cost-to-Charge Ratio Files (CCR) (HCUP. 2016. Agency for Healthcare Research and Quality, Rockville, MD. https://www.hcup-us.ahrq.gov/db/state/costtocharge.jsp) allowed for the conversion from charges to costs, but CCRs are only available for hospitalization charges and not for ED charges. 
national event type distribution. ${ }^{* * * *}$ Age-standardized per capita hospitalization costs, representing the overall cost per adult aged $\geq 18$ years living in the jurisdiction, are presented at the national and state levels.

State-level estimates for the number of Million Heartspreventable events and hospitalization costs (in 2016 US\$) expected to occur during 2017-2021 were calculated in two ways. For states with complete 2016 data (ED, hospitalization, and mortality estimates), the overall age-specific mutually exclusive rates for 2016 were applied to the projected state population estimates ${ }^{\dagger \dagger \dagger}$ during 2017-2021 and summed to determine the expected event totals; the 2016 mean stateand age-specific cost per hospitalization was applied to the expected hospitalization event total to estimate expected costs. For states with incomplete 2016 data, it was assumed that the proportional relationship across their ED, hospitalization and mortality rates were the same as the average calculated among states with complete data. If a state was missing 2016 hospitalization data, the national age-specific average cost per hospitalization event was applied to their expected age-specific hospitalization event totals and summed. Expected overall U.S. event totals and hospitalization costs during 2017-2021 equal the sum of the state-level estimates. $\$ \$ \$ \$ \$$

\section{Results}

Nationally, in 2016, over 2.2 million Million Hearts-preventable hospitalizations and 415,480 deaths occurred (Table 1). The hospitalizations resulted in an estimated $\$ 32.7$ billion in costs. For both event types, the burden was higher among men than among women (age-standardized hospitalization rates of 989.6 and 725.1 per 100,000 population, respectively, and mortality rates of 172.3 and 143.0 per 100,000, respectively) and increased with age. However, an estimated 805,000 hospitalizations and 75,245 deaths occurred among adults aged 18-64 years. Among all racial/ ethnic groups, the highest mortality rates were in non-Hispanic blacks (211.6 per 100,000). Acute myocardial infarctions and strokes accounted for approximately half $(47 \%)$ of hospitalizations (rates of 204.5 and 199.1 per 100,000, respectively) and approximately two thirds (61\%) of deaths (42.2 and 53.7 per 100,000,

\footnotetext{
**** Standardized to the 2010 decennial U.S. Census population and to the national distribution of events (percentage of events that were acute myocardial infarctions, strokes, precursor events, or other events) observed during 2016.

$1+t^{\dagger}$ State-level population projections were based on the linear extrapolation of 2016 July $1^{\text {st }}$ Census estimates and 2020 population projections provided by the University of Virginia's Weldon Cooper Center for Public Service (Available at https://demographics.coopercenter.org/national-populationprojections and accessed on May 1, 2018).

\$SSS The method used here to describe the number of events and total hospitalization cost expected at the national level differs from the method being used to officially track these estimates at the national level; that method uses estimates generated from using the NEDS, NIS, and NVSS (https://www.ahajournals.org/doi/10.1161/JAHA.117.006021).
}

respectively). "Other" cardiovascular events, which include those related to heart failure, contributed to $46 \%$ of hospitalizations and $38 \%$ of deaths (rates $=394.6$ and 59.8 per 100,000, respectively).

Age-standardized event rates per 100,000 population varied considerably across states with available data, including for treat-and-release ED visits (34 states and DC; range $=56.4$ [Connecticut] to 274.8 [Kentucky]), acute hospitalizations (46 states and DC; range $=484.0$ [Wyoming] to 1670.3 [DC]), and deaths (50 states and DC; range $=111.2$ [Vermont] to 267.3 [Mississippi]) (Table 2) (Supplementary Figure 1, https://stacks.cdc.gov/view/cdc/58168). Among the 35 jurisdictions with complete overall data, the three with the lowest overall mutually exclusive event rates were Utah (805.7), Wyoming (828.9), and Vermont (840.6) and those with the highest rates were DC $(2,048.2)$, Tennessee $(1,551.6)$, and Kentucky $(1,510.3)$ (Figure).

In 2016, the age-standardized per-capita hospitalization cost was $\$ 125$ in the United States, and ranged across states with available data from $\$ 76$, in New Mexico and Wyoming, to $\$ 294$, in DC (Table 2). The age- and event type-standardized mean cost per hospitalization was $\$ 16,274$ nationally and ranged from $\$ 11,307$ in Arkansas to $\$ 24,017$ in Alaska. If the 2016 overall mutually exclusive event rates were to remain constant during 2017-2021, an estimated 16.3 million events are expected to occur, including 2.2 million ED visits, 11.8 million hospitalizations, and 2.2 million deaths (Table 3) (Supplementary Table 2, https://stacks.cdc.gov/ view/cdc/58171); if mean hospitalization costs per event remained constant, an estimated $\$ 173.7$ billion in costs would be expected to occur. Preventing one million events during 2017-2021 would result in approximately a $6.1 \%$ reduction in expected event totals and associated costs.

\section{Conclusion and Comment}

The subset of cardiovascular events 9999 targeted for prevention by Million Hearts 2022 places a considerable burden on the health and economic well-being of Americans $(2,7)$. Despite these events being highly preventable (3), they accounted for approximately 2 million hospitalizations and 400,000 deaths in 2016. Furthermore, without a more concerted effort to improve CVD risk factors, an estimated 16.3 million nonfatal and fatal cardiovascular events and $\$ 173.7$ billion in hospitalization costs are expected to occur during 2017-2021.

\footnotetext{
9999 Overall, CVD accounts for approximately 800,000 deaths and an estimated $\$ 300$ billion in direct medical expenses and lost productivity annually (2). The subset of events targeted for prevention by Million Hearts 2022 activities was identified based on multiple factors described by Ritchey et al (https://www.ahajournals.org/doi/10.1161/JAHA.117.006021) with the most important factor being the preventability of the event by current or planned Million Hearts 2022 efforts.
} 
TABLE 1. National Million Hearts-preventable hospitalization and mortality rates (per 100,000 population) and hospitalization costs among adults aged $\geq 18$ years, by age group, gender, race-ethnicity* and event type, 2016

\begin{tabular}{|c|c|c|c|c|}
\hline Event & No., thousands $\left(\mathrm{SE}^{\dagger}\right)$ & $\operatorname{Cost}^{\S}\left(\mathrm{SE}^{\dagger}\right)$, in US\$ billions & Crude rate $\left(\mathrm{SE}^{\dagger}\right)$ & Age-standardized rate ${ }^{\Uparrow}\left(\mathrm{SE}^{\dagger}\right)$ \\
\hline \multicolumn{5}{|l|}{ Acute hospitalizations } \\
\hline Total & $2,238.3(24.6)$ & $32.7(0.29)$ & $897.2(9.9)$ & $850.9(5.8)$ \\
\hline Men (total) & $1,180.1(13.6)$ & $18.6(0.18)$ & $971.5(11.2)$ & $989.6(7.1)$ \\
\hline \multicolumn{5}{|l|}{ Age group (yrs), men } \\
\hline $18-44$ & $73.0(1.2)$ & $1.3(0.03)$ & $124.6(2.0)$ & - \\
\hline $45-64$ & $426.0(5.6)$ & $7.4(0.09)$ & $1,036.4(13.6)$ & - \\
\hline $65-74$ & $286.1(3.7)$ & $4.8(0.05)$ & $2,136.5(27.3)$ & - \\
\hline$\geq 75$ & $395.0(4.9)$ & $5.1(0.04)$ & $4,700.9(58.2)$ & - \\
\hline Women (total) & $1,057.2(11.4)$ & $14.1(0.12)$ & $825.8(8.9)$ & $725.1(5.1)$ \\
\hline \multicolumn{5}{|c|}{ Age group (yrs), women } \\
\hline $18-44$ & $46.9(0.9)$ & $0.8(0.02)$ & $81.6(1.5)$ & - \\
\hline $45-64$ & $258.7(3.5)$ & $4.1(0.05)$ & $599.6(8.0)$ & - \\
\hline $65-74$ & $231.1(2.8)$ & $3.3(0.03)$ & $1516.6(18.4)$ & - \\
\hline$\geq 75$ & $520.5(6.0)$ & $5.9(0.04)$ & $4,262.2(48.9)$ & - \\
\hline \multicolumn{5}{|l|}{ Event type } \\
\hline AMI & $536.3(8.7)$ & $11.6(0.09)$ & $215.0(3.5)$ & $204.5(2.0)$ \\
\hline Stroke & $524.3(7.5)$ & $8.4(0.12)$ & $210.2(3.0)$ & $199.1(1.8)$ \\
\hline Precursor** & $138.4(2.1)$ & $1.1(0.01)$ & $55.5(0.8)$ & $52.7(0.5)$ \\
\hline Other ${ }^{\dagger \dagger}$ & $1,039.3(11.0)$ & $11.6(0.14)$ & $416.6(4.4)$ & $394.6(2.9)$ \\
\hline \multicolumn{5}{|l|}{ Deaths } \\
\hline Total & 415.5 & NA & 166.5 & 157.4 \\
\hline Men (total) & 199.4 & NA & 164.1 & 172.3 \\
\hline \multicolumn{5}{|l|}{ Age group (yrs), men } \\
\hline $18-44$ & 5.2 & NA & 8.9 & - \\
\hline $45-64$ & 44.2 & NA & 107.6 & - \\
\hline $65-74$ & 42.0 & NA & 313.5 & - \\
\hline$\geq 75$ & 107.9 & NA & $1,284.4$ & - \\
\hline Women (total) & 216.1 & NA & 168.8 & 143.0 \\
\hline \multicolumn{5}{|c|}{ Age group (yrs), women } \\
\hline $18-44$ & 2.7 & NA & 4.7 & - \\
\hline $45-64$ & 23.1 & NA & 53.5 & - \\
\hline $65-74$ & 28.3 & NA & 185.4 & - \\
\hline$\geq 75$ & 162.1 & NA & $1,327.2$ & - \\
\hline \multicolumn{5}{|l|}{ Race/Ethnicity* } \\
\hline White, non-Hispanic & 320.2 & NA & 197.9 & 160.2 \\
\hline Black, non-Hispanic & 52.2 & NA & 170.6 & 211.6 \\
\hline Hispanic $§ \S$ & 25.4 & NA & 66.4 & 114.9 \\
\hline Other, non-Hispanic & 12.6 & NA & 75.2 & 97.1 \\
\hline Asian/PI & 10.6 & NA & 71.5 & 92.3 \\
\hline $\mathrm{Al} / \mathrm{AN}$ & 2.0 & NA & 103.6 & 132.9 \\
\hline \multicolumn{5}{|l|}{ Event type } \\
\hline AMI & 111.7 & NA & 44.8 & 42.2 \\
\hline Stroke & 141.8 & NA & 56.9 & 53.7 \\
\hline Precursor** & 4.4 & NA & 1.7 & 1.7 \\
\hline Other ${ }^{\dagger+}$ & 157.5 & NA & 63.1 & 59.8 \\
\hline
\end{tabular}

Sources: Agency for Healthcare Research and Quality's Healthcare Cost and Utilization Project (HCUP) National Inpatient Sample (NIS); National Center for Health Statistics' National Vital Statistics System Mortality Data.

Abbreviations: Al/AN = American Indian/Alaskan Native; $\mathrm{AMI}=$ acute myocardial infarction; Asian/PI = Asian/Pacific Islander; $\mathrm{NA}=$ not applicable; $\mathrm{SE}=$ standard error.

* Race/ethnicity information was consistently available nationally for only mortality data. During 1999-2011, the sensitivity for identifying the correct race and ethnicity on death certificates was 99.2\% (non-Hispanic whites), 98.1\% (non-Hispanic blacks), 91.3\% (Hispanics), 93.5\% (Asian/PI), and 73.3\% (Al/AN) (Arias E, Heron M, Hakes JK. The validity of race and Hispanic-origin reporting on death certificates in the United States: An update. National Center for Health Statistics. Vital Health Stat 2 2016;172:1-21. https://www.cdc.gov/nchs/data/series/sr_02/sr02_172.pdf).

+ Standard errors are provided only for acute hospitalization estimates as they are determined using a sample of hospitalizations (NIS) obtained from the HCUP State Inpatient Databases. No sampling error is produced when using mortality data from the National Vital Statistic System.

$\S$ Described by applying HCUP cost-to-charge ratios to the charges the hospitals billed for the entire hospital stay; these costs exclude professional (physician) fees (https://www.hcup-us.ahrq.gov/db/state/costtocharge.jsp). The age- and event type-standardized mean cost per event in the United States was \$16,274 per hospitalization and the age-standardized per-capita cost was $\$ 125$ per U.S. adult.

" Standardized by age to the 2010 U.S. Census population.

** Includes stable angina pectoris, transient ischemic attack, and other acute and subacute ischemic heart disease.

${ }^{\dagger \dagger}$ Includes heart failure, abdominal aortic aneurysm, atheroembolism (hospitalizations only), atherosclerosis and peripheral artery disease (deaths only), hypertension without heart failure, and cardiac arrest that had another Million Hearts-preventable event type coded as a secondary diagnosis or contributing cause of death.

$\S \S$ Persons with unspecified ethnicity were considered to be non-Hispanic (approximately $0.3 \%$ of deaths). 
TABLE 2. Age-standardized Million Hearts-preventable emergency department, hospitalization, mortality rates (per 100,000 population), hospitalization costs, and overall event totals among adults aged $\geq 18$ years, by state* — United States, 2016

\begin{tabular}{|c|c|c|c|c|c|c|c|}
\hline \multirow[b]{2}{*}{ State } & \multirow[b]{2}{*}{$\begin{array}{l}\text { Treat-and- } \\
\text { release } \\
\text { ED visit rate }\end{array}$} & \multicolumn{4}{|c|}{ Acute hospitalizations } & \multirow[b]{2}{*}{$\begin{array}{l}\text { Mortality } \\
\text { rate }^{\dagger}\end{array}$} & \multirow[b]{2}{*}{$\begin{array}{c}\text { Overall } \\
\text { event total } \\
\text { (thousands) }^{\dagger+}\end{array}$} \\
\hline & & Rate $^{\dagger}$ & $\begin{array}{c}\text { Cost, } \\
\text { in US\$ (2016) } \\
\text { billions }\end{array}$ & $\begin{array}{c}\text { Mean cost } \\
\text { (US\$) per event }{ }^{\S, \pi}\end{array}$ & $\begin{array}{l}\text { Per-capita costs } \\
(\text { US } \$)^{\S, * *}\end{array}$ & & \\
\hline Alabama & $-\S \S$ & -\$§ & -\$§ & $-\S \S$ & $-\S \S$ & 206.1 & $-\S \S$ \\
\hline Alaska & —§§ & 593.0 & 0.07 & 24,017 & 149 & 116.9 & —§§ \\
\hline Arizona & 132.8 & 666.7 & 0.56 & 14,935 & 97 & 114.4 & 53.9 \\
\hline Arkansas & 192.5 & 914.2 & 0.24 & 11,307 & 95 & 260.0 & 34.2 \\
\hline California & 154.7 & 698.3 & 4.21 & 23,092 & 143 & 146.4 & 294.9 \\
\hline Colorado & —§§ & 555.1 & 0.38 & 18,479 & 91 & 123.9 & —*** \\
\hline Connecticut & 56.4 & 773.5 & 0.42 & 19,256 & 133 & 120.5 & 30.1 \\
\hline Delaware & —§§ & —§§ & —§§ & —§§ & —§§ & 131.7 & —§§ \\
\hline District of Columbia 9 १ी & 202.0 & $1,670.3$ & 0.13 & 20,600 & 294 & 175.9 & 9.2 \\
\hline Florida & 113.4 & 916.0 & 2.30 & 13,907 & 116 & 134.3 & 235.1 \\
\hline Georgia & 233.5 & 928.6 & 0.89 & 14,171 & 117 & 188.9 & 101.0 \\
\hline Hawaii & 149.8 & 755.7 & 0.17 & 18,573 & 141 & 126.3 & 12.7 \\
\hline Idaho & —§§ & —§§ & —§§ & —§§ & —§§ & 156.3 & —§§ \\
\hline Illinois & 140.0 & 861.7 & 1.30 & 17,130 & 127 & 173.0 & 120.3 \\
\hline Indiana & 200.8 & 960.1 & 0.68 & 14,122 & 128 & 177.3 & 71.3 \\
\hline lowa & 199.2 & 670.7 & 0.24 & 15,442 & 90 & 138.0 & 27.8 \\
\hline Kansas & 184.5 & 754.3 & 0.22 & 13,507 & 96 & 168.1 & 26.1 \\
\hline Kentucky & 274.8 & $1,025.2$ & 0.56 & 16,591 & 153 & 210.3 & 55.2 \\
\hline Louisiana & —§§ & $1,097.0$ & 0.47 & 12,622 & 130 & 213.4 & —§§ \\
\hline Maine & 237.6 & 784.3 & 0.17 & 19,136 & 134 & 136.0 & 15.3 \\
\hline Maryland & 165.7 & 787.2 & 0.47 & 13,762 & 97 & 153.7 & 53.1 \\
\hline Massachusetts & $64.9 * * *$ & 839.1 & 0.78 & 20,720 & 135 & 129.1 & 60.4 \\
\hline Michigan & —§§ & $1,013.1$ & 1.11 & 14,937 & 131 & 176.3 & —§§ \\
\hline Minnesota & 127.4 & 659.7 & 0.52 & 20,228 & 114 & 113.1 & 40.9 \\
\hline Mississippi & —§§ & $1,040.0$ & 0.29 & 12,216 & 122 & 267.3 & —§§ \\
\hline Missouri & 179.9 & 999.5 & 0.71 & 14,813 & 138 & 202.1 & 71.3 \\
\hline Montana & 165.9 & 546.9 & 0.08 & 13,744 & 81 & 136.6 & 8.0 \\
\hline Nebraska & 142.9 & 645.0 & 0.16 & 17,866 & 104 & 141.7 & 14.4 \\
\hline Nevada & 169.3 & 804.1 & 0.27 & 14,105 & 115 & 134.0 & 25.4 \\
\hline New Hampshire & —§§ & —§§ & —§§ & —§§ & —§§ & 126.9 & —§§ \\
\hline New Jersey & 129.8 & 839.5 & 0.99 & 17,308 & 131 & 138.7 & 83.6 \\
\hline New Mexico & —§§ & 528.9 & 0.13 & 15,568 & 76 & 133.1 & —§§ \\
\hline New York & 91.1 & 803.9 & 2.28 & 19,676 & 138 & 134.8 & 169.9 \\
\hline North Carolina & 195.9 & 947.6 & 1.00 & 14,132 & 121 & 159.7 & 107.8 \\
\hline North Dakota & 162.8 & 912.4 & 0.09 & 18,224 & 157 & 134.8 & 7.3 \\
\hline Ohio & 190.8 & 996.8 & 1.33 & 14,866 & 134 & 176.4 & 136.6 \\
\hline Oklahoma & —§§ & 884.8 & 0.35 & 13,539 & 112 & 197.4 & _§§ \\
\hline Oregon & —§§ & 675.4 & 0.39 & 18,989 & 110 & 138.6 & —§§ \\
\hline
\end{tabular}

See table footnotes on next page.

Considerable disparities in event rates were evident. Nationally, non-Hispanic blacks continue to experience the highest CVD mortality rates $32 \%$ higher than those in non-Hispanic whites). This disparity is due, in part, to the high prevalence of uncontrolled blood pressure among blacks ( $)$, placing them at higher risk than other racial/ethnic groups for acute myocardial infarction, stroke, and other CVD conditions, including heart failure $(2,8)$. Additionally, despite the considerable increase in risk for a cardiovascular event with increasing age, in 2016, over 800,000 combined hospitalizations and deaths occurred among adults aged $<65$ years (approximately one in three events). Other studies have shown that decades-long improvement in heart disease and stroke mortality have stalled $(9,10)$ and that younger populations, especially those aged 35-64 years, are experiencing worse outcomes across the country $(4,9)$. In 2016, Million Hearts-preventable event rates among persons aged 35-64 years varied considerably by demographic characteristics and U.S. state (Supplementary Table 3, https://stacks.cdc. gov/view/cdc/58172); among the overall 16.3 million events expected to occur during 2017-2021 if no additional action is 
Morbidity and Mortality Weekly Report

TABLE 2. (Continued) Age-standardized Million Hearts-preventable emergency department, hospitalization, mortality rates (per 100,000 population), hospitalization costs, and overall event totals among adults aged $\geq 18$ years, by state ${ }^{*}$ - United States, 2016

\begin{tabular}{|c|c|c|c|c|c|c|c|}
\hline \multirow[b]{2}{*}{ State } & \multirow[b]{2}{*}{$\begin{array}{l}\text { Treat-and- } \\
\text { release } \\
\text { ED visit rate }^{\dagger}\end{array}$} & \multicolumn{4}{|c|}{ Acute hospitalizations } & \multirow[b]{2}{*}{$\begin{array}{l}\text { Mortality } \\
\text { rate }^{\dagger}\end{array}$} & \multirow[b]{2}{*}{$\begin{array}{c}\text { Overall } \\
\text { event total } \\
\text { (thousands) }^{\dagger+}\end{array}$} \\
\hline & & Rate $^{\dagger}$ & $\begin{array}{c}\text { Cost, } \\
\text { in US\$ (2016) } \\
\text { billions }\end{array}$ & $\begin{array}{c}\text { Mean cost } \\
\text { (US\$) per event }{ }^{\S, 9}\end{array}$ & $\begin{array}{l}\text { Per-capita costs } \\
\text { (US\$) })^{\S, * *}\end{array}$ & & \\
\hline Pennsylvania & _§§ & 987.3 & 1.55 & 15,986 & 133 & 162.5 & $-\S \S$ \\
\hline Rhode Island & 148.6 & 932.8 & 0.12 & 15,480 & 129 & 131.2 & 11.5 \\
\hline South Carolina & 235.8 & 921.8 & 0.49 & 14,125 & 118 & 169.1 & 55.4 \\
\hline South Dakota & 167.3 & 715.5 & 0.08 & 15,594 & 104 & 174.9 & 7.8 \\
\hline Tennessee & 236.6 & $1,121.0$ & 0.71 & 12,342 & 130 & 194.0 & 85.0 \\
\hline Texas & 201.7 & 893.7 & 2.48 & 15,654 & 129 & 168.9 & 239.1 \\
\hline Utah & 116.6 & 537.8 & 0.17 & 19,859 & 90 & 151.3 & 14.4 \\
\hline Vermont & 157.9 & 571.5 & 0.05 & 17,876 & 90 & 111.2 & 4.9 \\
\hline Virginia & —§§ & 866.4 & 0.77 & 15,727 & 115 & 154.6 & —§§ \\
\hline Washington & —§§ & 713.0 & 0.72 & 20,661 & 125 & 127.4 & —§§ \\
\hline West Virginia & —§§ & $1,030.9$ & 0.25 & 13,416 & 145 & 172.8 & —§§ \\
\hline Wisconsin & 145.7 & 730.7 & 0.55 & 17,107 & 111 & 148.6 & 51.2 \\
\hline Wyoming & 194.9 & 484.0 & 0.04 & 15,977 & 76 & 150.0 & 3.8 \\
\hline
\end{tabular}

Sources: Agency for Healthcare Research and Quality's Healthcare Cost and Utilization Project (HCUP), State Emergency Department Databases and State Inpatient Databases; National Center for Health Statistics' National Vital Statistics System Mortality Data.

Abbreviation: $\mathrm{ED}=$ emergency department.

* Calculated only for states where data were made available.

† Standardized by age to the 2010 U.S. Census population.

$\S$ Described by applying HCUP cost-to-charge ratios to the charges the hospitals billed for the entire hospital stay in each state; these costs exclude professional (physician) fees.

I Standardized by age to the 2010 U.S. Census population and by event type to the national distribution of events (acute myocardial infarctions, strokes, precursor events, and other cardiovascular events) observed during 2016.

** Represents the overall cost per adult aged $\geq 18$ years living in the jurisdiction, standardized by age to the 2010 U.S. Census population.

${ }^{+t}$ Represents the sum of number of treat-and-release ED visits, acute, nonfatal hospitalizations, and deaths that occurred in that jurisdiction.

$\S \S$ Data were not collected or were not available for analysis (treat-and-release ED data for Mississippi and Oregon are regularly collected, but 2016 data were not available at time of this report).

१ศ The ED and hospitalization event and cost values are likely overestimates for this location because these events are attributed to where the event was treated and not the residence of the patient.

*** Transfers to other acute care hospitals are not identified in discharge disposition codes, so they could not be excluded from the analysis and the rate may be slightly inflated.

taken, 5.0 million (30.9\%) are expected to occur among this age group (Supplementary Figure 2, https://stacks.cdc.gov/view/ cdc/58169). Therefore, implementation of strategies that focus on the prevention, early diagnosis, and effective management of CVD risk factors among younger adults is needed to prevent events in both the short- and long-term.

This is one of the first studies to demonstrate striking state-level variation in nonfatal cardiovascular event rates and hospitalization costs using data collected among adults of all ages and across all payer types, including the uninsured. Whereas the burden of state-level mortality was higher in the southeastern United States, which aligns with the findings from previous studies (2), rates for $\mathrm{ED}$ visits and hospitalizations were higher in both this region and elsewhere, including many Midwestern states. The overall state variation in nonfatal event rates and associated hospitalization costs is likely driven by both geographic differences in disease prevalence and severity, and differences in care delivery and public health quality $(2,11)$. Additional focus on improving the environments in which persons live, work, and play (e.g., built environment modifications to promote increased physical activity) (12), leveraging community resources to aid in CVD risk factor management (e.g., referral to nutritional and fitness counseling groups) (13), providing effective outpatient care (e.g., use of team-based care for hypertension and cholesterol management) (14), and improving the care received after a cardiovascular event (e.g., systematic referral to cardiac rehabilitation services for those with eligible diagnoses) (15) might reduce the need for and the expense of many of these acute care services.

This study uses the best available data to describe the burden of Million Hearts-preventable events at the national and state levels. However, the findings in this report are subject to at least six limitations. First, not all jurisdictions provided ED and/or hospitalization data; efforts to impute missing values might produce inaccurate estimates. Second, nonfatal events are attributed to treatment location and not patient residence, therefore jurisdictions in close proximity to large population centers in neighboring states (e.g., DC) could have overestimated or underestimated rates. Third, whereas the methodology used attempts to identify mutually exclusive events, there is potential for over- or undercounting events. Fourth, cardiovascular 
FIGURE. Age-standardized overall Million Hearts-preventable event* rates among adults aged $\geq 18$ years, by U.S. state, ${ }^{\dagger} 2016$

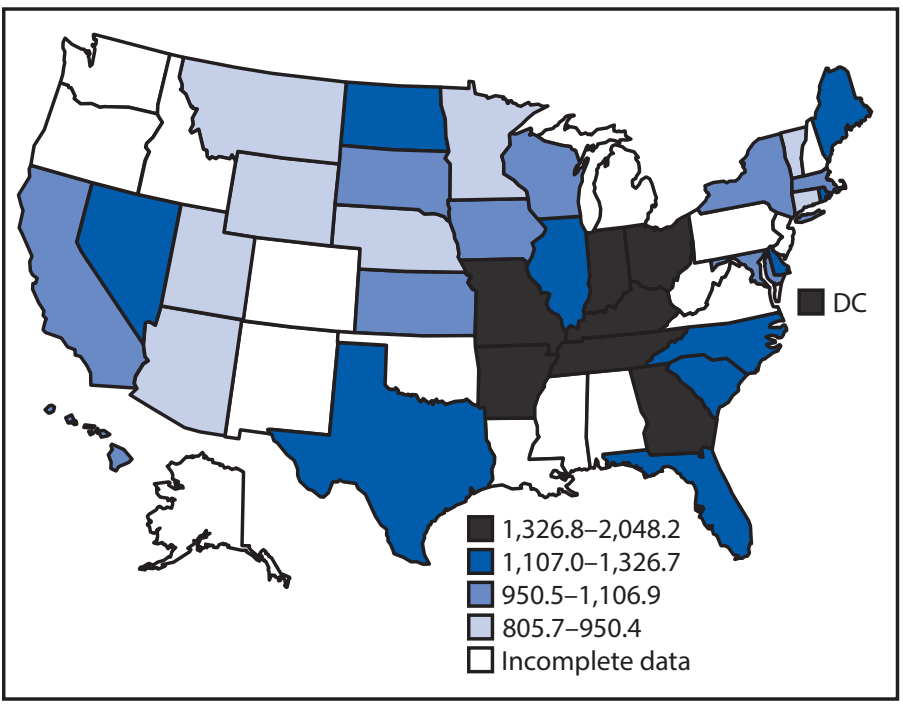

Sources: Agency for Healthcare Research and Quality's Healthcare Cost and Utilization Project State Emergency Department Databases and State Inpatient Databases; National Center for Health Statistics' National Vital Statistics System Mortality Data.

* Includes mutually exclusive nonfatal treat-and-release emergency department visits, nonfatal acute hospitalizations and deaths attributed to acute myocardial infarctions, strokes, precursor cardiovascular conditions (e.g., stable angina pectoris), and other cardiovascular conditions (e.g., heart failure).

† Complete data are available for 34 states and the District of Columbia (DC). Supplementary Figure 1 shows age-standardized rates of treat-and-release emergency department visits for 34 states and DC, hospitalizations for 46 states and DC, and mortality for 50 states and DC (https://stacks.cdc.gov/view/ cdc/58168).

events that do not result in ED or hospital use or death are not counted. Fifth, because administrative data are being used, differences in use of health care (e.g., changes in how events are medically managed) or coding practices (e.g., changes in how nonfatal events are billed) might affect the event rates and costs presented in this study rather than changes in disease burden. However, this study attempts to address differences in practice patterns by excluding elective hospitalizations and including certain ED events (e.g., heart failure-related visits). Finally, the hospitalization cost estimates are likely conservative, as they do not include professional (physician) fees, and costs were not available for treat-and-release ED visits.

Each state would need to realize an approximate $6 \%$ decrease in its expected event totals during 2017-2021 to collectively prevent one million events at the national level. This is feasible if clinical and public health partners in every state mobilize and strengthen their focus on implementing the prevention strategies outlined by Million Hearts 2022 (https://millionhearts.hhs.gov/files/MH-Framework.pdf) to achieve $80 \%$ or greater performance on the ABCS and at least a $20 \%$ reduction in physical inactivity, tobacco use prevalence, and sodium consumption (16).

\section{Summary}

What is already known about this topic?

The health and economic burden of cardiovascular disease is considerable. Million Hearts 2022 supports use of evidencebased clinical and community strategies to prevent one million cardiovascular events during 2017-2021.

What is added by this report?

Nationally, in 2016, 2.2 million hospitalizations, costing \$32.7 billion, and 415,480 deaths occurred that are being targeted for prevention by Million Hearts 2022, with disparities across demographic characteristics and states. Approximately 16.3 million events could occur during 2017-2021 without preventive intervention.

What are the implications for public health practice?

Achieving the Million Hearts 2022 goal likely requires states to focus on using prevention strategies that best meet the cardiovascular health needs of the persons they serve.

\section{Acknowledgments}

State data organizations that contributed data to the Agency for Healthcare Research and Quality's Healthcare Cost and Utilization Project: Alaska Department of Health and Social Services, Alaska State Hospital and Nursing Home Association, Arizona Department of Health Services, Arkansas Department of Health, California Office of Statewide Health Planning and Development, Colorado Hospital Association, Connecticut Hospital Association, District of Columbia Hospital Association, Florida Agency for Health Care Administration, Georgia Hospital Association, Hawaii Health Information Corporation, Illinois Department of Public Health, Indiana Hospital Association, Iowa Hospital Association, Kansas Hospital Association, Kentucky Cabinet for Health and Family Services, Louisiana Department of Health, Maine Health Data Organization, Maryland Health Services Cost Review Commission, Massachusetts Center for Health Information and Analysis, Michigan Health \& Hospital Association, Minnesota Hospital Association, Mississippi State Department of Health, Missouri Hospital Industry Data Institute, Montana Hospital Association, Nebraska Hospital Association, Nevada Department of Health and Human Services, New Hampshire Department of Health \& Human Services, New Jersey Department of Health, New Mexico Department of Health, New York State Department of Health, North Carolina Department of Health and Human Services, North Dakota, Ohio Hospital Association, Oklahoma State Department of Health, Oregon Association of Hospitals and Health Systems, Oregon Office of Health Analytics, Pennsylvania Health Care Cost Containment Council, Rhode Island Department of Health, South Carolina Revenue and Fiscal Affairs Office, South Dakota Association of Healthcare Organizations, Tennessee Hospital Association, Texas Department of State Health Services, Utah Department of Health, Vermont Association of Hospitals and Health Systems, Virginia Health Information, Washington State Department of Health, West Virginia Department of Health and Human Resources, West Virginia Health Care Authority, Wisconsin Department of Health Services, Wyoming Hospital Association; Marguerite Barrett, M.L. Barrett, Inc; Molly Bailey, Truven-IBM Watson; Minya Sheng, Truven-IBM Watson; Linda Schieb, CDC. 
TABLE 3. Expected number of Million Hearts-preventable events and hospitalization costs among adults aged $\geq 18$ years during $2017-2021$, nationally and by state - United States*

\begin{tabular}{|c|c|c|c|c|c|}
\hline \multirow[b]{2}{*}{ State } & \multicolumn{4}{|c|}{ Expected event totals, in thousands } & \multirow[b]{2}{*}{$\begin{array}{c}\text { Expected } \\
\text { hospitalization costs, } \\
\text { in US\$ (2016) billions }\end{array}$} \\
\hline & $\begin{array}{c}\text { Treat-and-release } \\
\text { ED visits }\end{array}$ & $\begin{array}{c}\text { Acute } \\
\text { hospitalizations }\end{array}$ & Deaths & $\begin{array}{c}\text { Total } \\
\text { mutually exclusive } \\
\text { events }\end{array}$ & \\
\hline United States & $2,231.3$ & $11,843.8$ & $2,214.0$ & $16,289.1$ & 173.7 \\
\hline Alabama & $48.4^{\dagger}$ & $255.5^{\S}$ & 44.1 & 347.9 ? & $3.8^{\S}$ \\
\hline Alaska & $2.8^{\dagger}$ & 14.7 & 2.6 & $20.1^{9}$ & 0.4 \\
\hline Arizona & 39.9 & 200.9 & 35.5 & 276.3 & 2.9 \\
\hline Arkansas & 24.7 & 118.1 & 34.5 & 177.3 & 1.2 \\
\hline California & 241.4 & $1,088.6$ & 229.0 & $1,558.9$ & 22.3 \\
\hline Colorado & $23.5^{\dagger}$ & 122.1 & 26.5 & $172.0^{9}$ & 2.0 \\
\hline Connecticut & 9.6 & 131.0 & 21.1 & 161.7 & 2.2 \\
\hline Delaware & $6.2^{\dagger}$ & $32.9^{\S}$ & 6.1 & $45.3^{\Uparrow}$ & $0.5^{\S}$ \\
\hline District of Columbia & 4.9 & 40.2 & 4.0 & 49.1 & 0.7 \\
\hline Florida & 113.9 & 945.2 & 147.7 & $1,206.8$ & 11.8 \\
\hline Georgia & 94.2 & 374.7 & 74.6 & 543.5 & 4.8 \\
\hline Hawaii & 9.7 & 50.4 & 8.9 & 69.0 & 0.9 \\
\hline Idaho & $11.4^{\dagger}$ & $60.8^{\S}$ & 11.7 & $83.8^{\Re}$ & $0.9^{\S}$ \\
\hline Illinois & 74.1 & 458.2 & 93.0 & 625.4 & 6.7 \\
\hline Indiana & 56.4 & 270.9 & 50.7 & 377.9 & 3.6 \\
\hline lowa & 28.7 & 96.0 & 20.7 & 145.4 & 1.3 \\
\hline Kansas & 22.7 & 92.4 & 21.2 & 136.3 & 1.2 \\
\hline Kentucky & 52.8 & 197.9 & 40.9 & 291.6 & 2.9 \\
\hline Louisiana & $39.0^{\dagger}$ & 201.7 & 38.5 & $279.3^{\pi}$ & 2.4 \\
\hline Maine & 17.0 & 55.3 & 9.9 & 82.3 & 0.9 \\
\hline Maryland & 41.7 & 199.6 & 38.9 & 280.2 & 2.5 \\
\hline Massachusetts & 19.6 & 254.8 & 39.5 & 314.0 & 4.1 \\
\hline Michigan & $84.7^{\dagger}$ & 457.2 & 81.6 & $623.5^{9}$ & 5.9 \\
\hline Minnesota & 31.1 & 159.4 & 28.0 & 218.4 & 2.7 \\
\hline Mississippi & $25.8^{\dagger}$ & 126.5 & 32.7 & $185.0^{\natural}$ & 1.5 \\
\hline Missouri & 48.5 & 270.2 & 56.5 & 375.3 & 3.7 \\
\hline Montana & 8.7 & 27.9 & 7.2 & 43.8 & 0.4 \\
\hline Nebraska & 11.7 & 52.6 & 11.9 & 76.2 & 0.8 \\
\hline Nevada & 19.5 & 93.3 & 15.2 & 128.0 & 1.3 \\
\hline New Hampshire & $7.6^{\dagger}$ & $40.9^{\S}$ & 8.1 & $56.6^{\mathbb{9}}$ & $0.6^{\S}$ \\
\hline New Jersey & 50.1 & 328.9 & 55.2 & 434.2 & 5.1 \\
\hline
\end{tabular}

See table footnotes on next page.

Corresponding Author: Matthew Ritchey, mritchey@cdc.gov, 770-488-7232.

\footnotetext{
${ }^{1}$ Division for Heart Disease and Stroke Prevention, CDC; ${ }^{2}$ Center for Delivery, Organization and Markets, Agency for Healthcare Research and Quality, Rockville, Maryland.

All authors have completed and submitted the ICMJE form for disclosure of potential conflicts of interest. No potential conflicts of interest were disclosed.
}

\section{References}

1. Frieden TR, Berwick DM. The "Million Hearts" initiative—-preventing heart attacks and strokes. N Engl J Med 2011;365:e27. https://doi. org/10.1056/NEJMp1110421

2. Benjamin EJ, Virani SS, Callaway CW, et al.; American Heart Association Council on Epidemiology and Prevention Statistics Committee and Stroke Statistics Subcommittee. Heart disease and stroke statistics-2018 update: A report from the American Heart Association. Circulation 2018;137:e67-492. https://doi.org/10.1161/CIR.0000000000000558
3. CDC. Vital signs: avoidable deaths from heart disease, stroke, and hypertensive disease - United States, 2001-2010. MMWR Morb Mortal Wkly Rep 2013;62:721-7.

4. Vaughan AS, Ritchey MD, Hannan J, Kramer MR, Casper M. Widespread recent increases in county-level heart disease mortality across age groups. Ann Epidemiol 2017;27:796-800. https://doi.org/10.1016/j. annepidem.2017.10.012

5. Millon Hearts. Million Hearts 2022—preventing 1 million heart attacks and strokes by 2022. Washington, DC: US Department of Health and Human Services, CDC; 2018. https://millionhearts.hhs.gov/files/ MH-2022-Fact-Sheet.pdf

6. Wall HK, Ritchey MD, Gillespie C, Omura JO, Jamal A, George MG. Vital signs: prevalence of key cardiovascular disease risk factors for Million Hearts 2022-United States, 2011-2016. MMWR Morb Mortal Wkly Rep 2018;67:983-91.

7. Ritchey MD, Loustalot F, Wall HK, et al. Million Hearts: description of the national surveillance and modeling methodology used to monitor the number of cardiovascular events prevented during 2012-2016. J Am Heart Assoc 2017;6:e006021. https://doi.org/10.1161/ JAHA.117.006021 
Morbidity and Mortality Weekly Report

TABLE 3. (Continued) Expected number of Million Hearts-preventable events and hospitalization costs among adults aged $\geq 18$ years during 2017-2021, nationally and by state - United States*

\begin{tabular}{|c|c|c|c|c|c|}
\hline \multirow[b]{2}{*}{ State } & \multicolumn{4}{|c|}{ Expected event totals, in thousands } & \multirow[b]{2}{*}{$\begin{array}{c}\text { Expected } \\
\text { hospitalization costs } \\
\text { in US\$ }(2016) \text { billions }\end{array}$} \\
\hline & $\begin{array}{c}\text { Treat-and-release } \\
\text { ED visits }\end{array}$ & $\begin{array}{c}\text { Acute } \\
\text { hospitalizations }\end{array}$ & Deaths & $\begin{array}{c}\text { Total } \\
\text { mutually exclusive } \\
\text { events }\end{array}$ & \\
\hline New Mexico & $9.7^{\dagger}$ & 49.2 & 12.6 & $71.5^{\text {ๆ }}$ & 0.7 \\
\hline New York & 77.8 & 692.1 & 119.3 & 889.2 & 11.8 \\
\hline North Carolina & 87.8 & 425.9 & 73.1 & 586.7 & 5.4 \\
\hline North Dakota & 5.4 & 30.2 & 4.5 & 40.1 & 0.5 \\
\hline Ohio & 99.4 & 524.3 & 95.3 & 718.9 & 7.0 \\
\hline Oklahoma & $28.2^{\dagger}$ & 143.6 & 32.4 & $204.1^{9}$ & 1.8 \\
\hline Oregon & $24.3^{\dagger}$ & 128.7 & 27.3 & $180.3^{\natural}$ & 2.1 \\
\hline Pennsylvania & $110.7^{\dagger}$ & 606.3 & 103.7 & $820.6^{\natural}$ & 8.0 \\
\hline Rhode Island & 7.2 & 45.6 & 6.6 & 59.3 & 0.6 \\
\hline South Carolina & 52.7 & 207.3 & 38.9 & 298.8 & 2.6 \\
\hline South Dakota & 6.6 & 28.2 & 7.1 & 41.9 & 0.4 \\
\hline Tennessee & 68.1 & 327.2 & 57.3 & 452.6 & 3.8 \\
\hline Texas & 207.2 & 917.2 & 167.6 & $1,291.9$ & 13.4 \\
\hline Utah & 11.6 & 53.5 & 14.6 & 79.8 & 0.9 \\
\hline Vermont & 4.9 & 17.5 & 3.4 & 25.9 & 0.3 \\
\hline Virginia & $57.2^{\dagger}$ & 306.6 & 54.4 & $418.2^{9}$ & 4.1 \\
\hline Washington & $41.4^{\dagger}$ & 223.8 & 40.0 & $305.2^{9}$ & 3.9 \\
\hline West Virginia & $17.4^{\dagger}$ & 93.9 & 16.3 & $127.7^{\uparrow}$ & 1.3 \\
\hline Wisconsin & 38.7 & 192.2 & 40.0 & 270.9 & 2.9 \\
\hline Wyoming & 4.8 & 11.9 & 3.7 & 20.4 & 0.2 \\
\hline
\end{tabular}

Sources: Agency for Healthcare Research and Quality's Healthcare Cost and Utilization Project State Emergency Department Databases (from all states except Alabama, Alaska, Colorado, Delaware, Idaho, Louisiana, Michigan, Mississippi, New Hampshire, New Mexico, Oklahoma, Oregon, Pennsylvania, Virginia, Washington and West Virginia; ED data for Mississippi and Oregon are regularly collected, but 2016 data were not available at time of this report) and State Inpatient Databases (from all states except Alabama, Delaware, Idaho, and New Hampshire); National Center for Health Statistics' National Vital Statistics System Mortality Data.

Abbreviation: $\mathrm{ED}=$ emergency department.

* State-level estimates for the number of Million Hearts-preventable events (those targeted for prevention by the initiative) and hospitalization costs expected to occur during 2017-2021 were calculated in two ways. For states with complete 2016 data (ED, hospitalization, and mortality estimates), the overall age-specific mutually exclusive rates for 2016 were applied to the projected state population estimates during 2017-2021 and summed to determine the expected event totals; the 2016 mean state- and age-specific cost per hospitalization was applied to the expected hospitalization event total to estimate expected costs. For states with incomplete 2016 data, it was assumed that the proportional relationship across their ED, hospitalization, and mortality rates was the same as the average calculated among states with complete data. If a state was missing 2016 hospitalization data, the national age-specific average cost per hospitalization event was applied to their expected age-specific hospitalization event totals and summed. Expected overall U.S. event totals and costs during 2017-2021 equals the sum of the state-level estimates; this method differs from the method being used to officially track these estimates at the national level.

† ED rate was missing, therefore, an estimate was used.

$\S$ Hospitalization rate and cost per hospitalization information were missing, therefore, estimates were used.

" Calculated by using estimated ED visit rates and, where applicable, estimated hospitalization rates and summing those resultant event counts with the known death counts.

8. Heidenreich PA, Albert NM, Allen LA, et al.; American Heart Association Advocacy Coordinating Committee; Council on Arteriosclerosis, Thrombosis and Vascular Biology; Council on Cardiovascular Radiology and Intervention; Council on Clinical Cardiology; Council on Epidemiology and Prevention; Stroke Council. Forecasting the impact of heart failure in the United States: a policy statement from the American Heart Association. Circ Heart Fail 2013;6:606-19. https:// doi.org/10.1161/HHF.0b013e318291329a

9. Yang Q, Tong X, Schieb L, et al. Vital signs: recent trends in stroke death rates-United States, 2000-2015. MMWR Morb Mortal Wkly Rep 2017;66:933-9. https://doi.org/10.15585/mmwr.mm6635e1

10. Sidney S, Quesenberry CP Jr, Jaffe MG, et al. Recent trends in cardiovascular mortality in the United States and public health goals. JAMA Cardiol 2016;1:594-9. https://doi.org/10.1001/ jamacardio.2016.1326

11. Wakim R, Ritchey M, Hockenberry J, Casper M. Geographic variations in incremental costs of heart disease among Medicare beneficiaries, by type of service, 2012. Prev Chronic Dis 2016;13:E180. https://doi. org/10.5888/pcd13.160209
12. The Community Guide. Physical activity: Built environment approaches combining transportation system interventions with land use and environmental design. Atlanta, GA: The Community Guide; 2016. https://www.thecommunityguide.org/findings/ physical-activity-built-environment-approaches

13. Diabetes Prevention Program (DPP) Research Group. The Diabetes Prevention Program (DPP): description of lifestyle intervention. Diabetes Care 2002;25:2165-71. https://doi.org/10.2337/diacare.25.12.2165

14. Proia KK, Thota AB, Njie GJ, et al.; Community Preventive Services Task Force. Team-based care and improved blood pressure control: a community guide systematic review. Am J Prev Med 2014;47:86-99. https://doi.org/10.1016/j.amepre.2014.03.004

15. Ades PA, Keteyian SJ, Wright JS, et al. Increasing cardiac rehabilitation participation from 20\% to $70 \%$ : A road map from the Million Hearts Cardiac Rehabilitation Collaborative. Mayo Clin Proc 2017;92:234-42. https://doi.org/10.1016/j.mayocp.2016.10.014

16. Frieden TR, Wright JS, Conway PH. Is rapid health improvement possible? Lessons from the Million Hearts Initiative. Circulation 2017;135:1677_ 80. https://doi.org/10.1161/CIRCULATIONAHA.117.027461 